DOI 10.37882/2500-3682.2021.04.06

\title{
ОПЫТ И ВОСПРИЯТИЕ ПОЖИЛЫМИ ЛЮДЬМИ ЦИФРОВЫХ ТЕХНОЛОГИЙ И ИХ АДАПТАЦИЯ В ИНФОРМАЦИОННОМ ОБЩЕСТВЕ
}

\section{OLDER PEOPLE'S EXPERIENCE AND PERCEPTION OF DIGITAL TECHNOLOGIES AND THEIR ADAPTATION IN THE INFORMATION SOCIETY}

\section{E. Valishin}

Summary: Today, in most developed nations are the following important social trends observed: an aging population and the introduction of digital technologies into the life of society. However, research shows, that older people use digital technology less often compared to other age groups. The article deals with the use and non-use of digital technologies (Internet, computers, mobile phones) by older people. The author make an attention to the reluctance of using the capabilities of digital technologies and how it may be associated with the functional characteristics of these technologies and social attitudes, and not only with the age characteristics of older people. The age, education, attitudes and personal characteristics of older people influence how they relate to digital technology. The author's analysis allows us to combine behavioral, functional and physical factors with socio-demographic indicators to assess the use and non-use of digital technologies by older people.

Keywords: elderly people, «third age», digital technologies, social attitudes, usage of digital technologies.

\author{
Валишин Евгений Николаевич \\ K.nсх.н., дочент, Финансовый университет при \\ Правительстве Российской Федерации \\ ewgeni-v@rambler.ru
}

Аннотация: В настоящее время в большинстве развитых стран наблюдаются следующие важные социальные тенденции: старение населения и внедрение цифровых технологий в жизнь общества. Однако, исследования показывают, что пожилые люди используют цифровые технологии реже по сравнению с другими возрастными группами. В статье рассматриваются вопросы использование и неиспользование цифровых технологий (Интернет, компьютеры, мобильные телефоны) пожилыми людьми. Автор считает, что нежелание использовать возможности цифровых технологий может быть связано с функциональными особенностями данных технологий и социальными установками, а не с возрастными особенностями пожилых людей. Возраст, образование, установки и личностные особенности пожилых людей влияют на то, как они относятся к цифровым технологиям. Проведенный автором анализ позволяет объединить поведенческие, функциональные и физические факторы с социально-демографическими показателями для оценки использования и неиспользования цифровых технологий пожилыми людьми.

Ключевые слова: пожилые люди, «третий возраст», цифровые технологии, социальные установки, использование цифровых технологий. ожилые люди (люди «третьего возраста») - это самая быстрорастущая демографическая группа во всех странах, и не только в Российской Федерации, но и в развивающихся странах. В то же время недостаточно исследованным остается вопрос об особенностях адаптивного поведения людей пожилого возраста при использовании и неиспользовании цифровых технологий. Использование цифровых технологий может быть использован как своеобразный ресурс при адаптации к изменениям в обществе пожилыми людьми.

Анализ качественных данных показывает всеобщее положительное восприятие цифровых технологий, а также влияние отношений между разными возрастными группами и семейных отношений для использования цифровых технологий. Лица в возрасте 65-70 лет с высшим образованием и / или проживающие с супругом / партнеры чаще использовали цифровые технологии. Напротив, использование информационных и коммуникационных технологий (цифровые технологии) пожилыми людьми находится на значительно низком уровне, что приводит к возрастному цифровому разрыву.

В настоящее время проведенные исследования в различных странах обращают свое внимание на «цифровой разрыв» (Digital Divide), который означает, что доступ к Интернет-технологиям (виртуальному пространству) и наличие (или отсутствие) цифровых компетенций дает возможность индивиду присутствовать в определенной точке виртуального пространства. Исследования показывают, что «пожилые люди, по сравнению с более молодыми, чаще используют устаревшие технологии, сложнее принимают новые» [1].

Например, в 2017 году в 27 странах Европейского Союза только 20\% людей в возрасте от 64 до 74 лет использовали Интернет достаточно часто (то есть каждый день или почти каждый день), по сравнению с $81 \%$ людей в возрасте от 16 до 64 лет. 24 года и 63\% лиц в возрасте от 25 до 54 лет [6]. Более того, 65\% пожилых людей в странах ЕС никогда не пользовались Интернетом. 
Для анализа имеющиеся трудностей у людей «третьего возраста» (пожилых) при использовании цифровых технологий мы исследовали ряд социально-демографических показателей и набор факторов, найденных в литературе. Эта ассоциация помогла нам понять, почему и как пожилые люди используют информационные технологии и почему они этого не делают, что в конечном итоге способствует их принятию технологий.

Однако, предоставляемые посредством Интернета информация может помочь снизить социальную изоляцию пожилых людей, тогда как услуги такие как поиск, онлайн-банкинг и покупки помогут сделать реальную жизнь пожилых людей более качественной. Конечно, цифровые технологии приносят не только положительные результаты для пожилых людей, они могут иметь и обратные стороны, исследования показывают, что Интернет оказывает преимущественно положительное влияние на общительность, социальный капитал и благополучие.

Проведенные в настоящее время исследования показывают позитивное действие цифровых технологий в процессе социализацию людей «третьего возраста» (пожилых) к современному обществу: формируется достаточно стабильное чувство достижения определенного результата, повышается уровень знания собственных правовых возможностей для создания необходимого уровня социальных отношений, возрастает степень удовлетворенности и самостоятельности, оптимизация финансовых средств и более содержательное использование имеющегося временного ресурса». Использование цифровых технологий дает возможность пожилым людям быть более мобильными, повышаются их возможности в процессе делового и личного общения, приобретаются новые знания, умения и навыки необходимые для социализации в современное общество.

Однако, сегодня необходимо решать вопрос адаптации людей «третьего возраста» в новую для них реальность, которая связана с цифровыми технологиями. Необходимо уточнить позитивные и негативные последствия, возникающие при адаптации данной категории населения к инновациям в цифровых технологиях. Опросы показывают, что, большинство пожилых людей («третьего возраста») не изменили еще, в полной мере, своего отношения к использование цифровых технологий, хотя и указывают на преимущества, которые они дают. Отрицательное отношение людей «третьего возраста» (пожилых) к новым технологиям зачастую связано с опасениями по изменению повседневного образа жизни и низким уровнем мотивации (желания) к освоению чего-то нового. На степень доверия к новым технологиям пожилых людей и желание их использовать достаточно сильное влияние оказывает оценка того как эти технологии используются другими и насколько они не противоречат мотивационно - потребностной сфере данной категории людей. Кроме этого, прослеживается определенная взаимосвязь с особенностями образа жизни, социальным статусом, накопленным опытом (например, нежелание что-то менять, изменяться), полученным образованием, финансовым положением и т.д., что может повлиять на их отношение к цифровым технологиям.

Также и внешние факторы влияют на отношение людей «третьего возраста» к цифровым технологиям: «сложность и высокая стоимость оборудования, отсутствие поддержки во время учебного процесса, несоответствующие дидактические подходы в формировании необходимых навыков, высокая скорость инструкций, сложность пользовательского интерфейса, отсутствие поддержки со стороны семьи и др. Все это негативно сказывается на самооценке и осознании своих возможностей пожилыми людьми.

При этом следует учесть, что, во-первых, пожилые люди уже испытывают на себе социально-экономическое неравенство в силу своего возраста, а во-вторых, определенные госуслуги переводятся только на онлайн-доступ, так например, многие НПФ реализуют свои программы корпоративного пенсионного обеспечения через услуги личного кабинета, на сайте mos.ru люди так же могут ознакомиться с информацией связанной с посещением социальных служб, поликлиник, институтов власти, не имея доступа к ним или испытывая недостаток в них - цифровая грамотность в использовании электронных услуг может способствовать усилению возрастного неравенства. Сегодня, как никогда стали актуальными вопросы связанные с цифровизацией повседневных необходимых процессов, таких как получение и оформление пенсий, пособий, ряда социальных услуг.

На сегодняшний день, важнейшим приоритетом в работе клиент ориентированных НПФ (негосударственных пенсионных фондов) становится цифровизация, которая предполагает существенный рост доли диджитал коммуникаций с клиентами, а также перевод в цифровой формат внутренних процессов бизнеса.

С учетом этих возможностей и ограничений, а также пересечения двух социальных тенденций - старения населения и медленного освоения цифровые технологии этим стареющим, мы рассмотрели использование и неиспользование мобильных телефонов, компьютеров и Интернета среди пожилых людей, а так же людей среднего возраста. Несмотря на то, что в литературе показано, что возраст является основным для использования цифровых технологий пожилыми людьми, так же другие факторы могут играть роль в использовании и неиспользовании цифровых технологий. В частности, можно рассмотреть факторы, которые отличают активных пользователей от людей не использующих данные техноло- 
гии. Использование цифровых технологий пожилыми людьми за последнее десятилетие увеличилось, но использование компьютеров и Интернета по-прежнему отрицательно коррелирует с возрастом, его социальным статусом до выхода на пенсию, образованием, доходом. Это также означает, что использование цифровых технологий различается и у самих пожилых людей: 65-летний с большей вероятностью будет использовать цифровые технологии, чем 80-летний.

Однако использование мобильных телефонов не зависит в такой степени от возраста; скорее это связано с характеристиками работы (полный рабочий день, неполный рабочий день), доходом, образованием и семейным положением. По сравнению с пользователями мобильных телефонов, люди, не пользующиеся мобильными телефонами, с большей вероятностью работали неполный рабочий день, имели более низкий доход и уровень образования, были одинокими или бездетными. Помимо этих социально-демографических показателей, можно говорить о ряде факторов, объясняющих использование и неиспользование цифровых технологий пожилыми людьми. В то же время недавние исследования показывают, что пожилые люди не страдают технофобией, хотят использовать цифровые технологии и часто делают это с умением.

Основными причинами отказа от использования мобильных телефонов, указанными в опросе, были: «Не нужно» (34,2\%), «Не знаю, как им пользоваться» $(21,7 \%)$ и «Это дорого» (17,4\%).). В качественных интервью участники сообщили о трудностях с такими функциями, как отправка текстовых сообщений или более сложные функции. Острота зрения и физические характеристики мобильных телефонов, такие как маленькие экраны и маленькие кнопки, были основными причинами ограниченного использования. Только один из респондентов в полной мере использовал мобильный телефон: «Я почти все делаю с его помощью, даже оплачиваю свои счета онлайн. Отрицательные аспекты, указанные в интервью, касались затрат как для пользователей мобильных телефонов, так и для тех, кто не пользуется ими.

Нежелательные последствия использования цифровых технологий людьми «третьего возраста» (пожилыми людьми). Возрастают угрозы, которые связанны с процессом социализации: снижение времени контактов личностного общения и увеличение времени общения в виртуальном пространстве (Интернете) и по мобильному телефону. Недостаточная компьютерная компетентность снижают стоимость людей «третьего возраста» (пожилого человека) на рынке труда. Проведенный анализ позволяет утверждать, что цифровые технологии, при всей неоднозначности их использования людьми «третьего возраста» позволяют увеличивать личные ресурсы, которые необходимы для адаптации к инноваци- ям в обществе.

Можно выделить три группы факторов, которые влияют на принятие решение о неиспользовании цифровых технологий:

1. Установочные: они хотят попробовать, но не особо заинтересованы; или они не чувствуют себя уверенно, используя цифровые технологии; или они не полностью осознают преимущества технологии.

2. Функциональные: у них отсутствует домашний компьютер с доступом в Интернет и/или отсутствуют необходимые навыки (цифровая грамотность).

3. Физические: они ограничены физически или умственно, а это означает, что использование компьютера нецелесообразно или даже не стоит того. Эти ограничения обычно связаны с возрастом.

В случае установочных факторов - это компьютерная тревожность и интерес к цифровым технологиям, тесно связаны с использование данных технологий. С одной стороны, низкая уверенность в способности пожилых людей овладеть цифровыми технологиями может объяснять непринятие или низкий уровень использования. С другой стороны, пожилые люди сообщают об отсутствии интереса и потребности к технологиям. Но «для многих респондентов отсутствие интереса вызвано неправильным представлением о компьютерах - о том, что они не подходят для пожилых людей, слишком сложны или бесполезны» [7].

Что касается функциональных факторов, отсутствие компьютера и / или Интернета и / или отсутствие цифровой грамотности также являются одной из наиболее часто упоминаемых причин неиспользования цифровых технологий. Отсутствие доступа к компьютеру и / или Интернету также может быть связано с финансовыми условиями, поскольку экономические факторы играют роль в усвоении цифровых технологий пожилыми людьми.

Что касается физических факторов, физические проблемы могут положительно или отрицательно повлиять на использование компьютера и Интернета. Если проблема носит визуальный характер или связана с артритом, ожидается, что использование цифровых технологий пострадает от этого. Но если проблема связана с мобильностью, пользователи могут проводить больше времени в сети, чем те, кто не привязан к дому. В случае мобильных телефонов пожилые люди сообщают, что их использование мобильных телефонов ограничено некоторыми функциями, такими как маленькие кнопки, использование ватсап и т.п. не возможно на старых моделях телефонов, а новые смартфоны требуют обучения другим расширенным функциями, а учиться уже нет желания. Эти функции обычно воспринимаются как не- 
удобные для пользователя из-за возрастных физических ограничений.

Некоторые возрастные слабости влияют на внедрение цифровых технологий, особенно среди пожилых людей. Например, когнитивные изменения могут повлиять на принятие и использование технологий: увеличение возраста связано с некоторыми потерями когнитивных функций, в частности, общего подвижного интеллекта (Gf) - критического фактора в обучении. Тем не менее, некоторые исследования показывают, что производительность Gf можно улучшить тренировкой [4]; и что кристаллизованный интеллект, связанный с опытом и приобретенными знаниями, увеличивается или стабилизируется с возрастом.

Основными причинами принятия и использования цифровых технологий в основном являются отношение, а именно интерес и предполагаемая полезность. Эти факторы связаны с использованием компьютеров для обработки текстов, доступа в Интернет, а также для электронной почты и социальных сетей. Эти три основных фактора - поведенческий, функциональный и физический - дают нам более полную картину отказа от цифровых технологий и их принятия. Модели внедрения цифровых технологий включают ряд переменных от отношения к ним и социально-демографических до компонентных способностей; или конкретные индикаторы, такие как предложенные моделью принятия технологий, а именно: воспринимаемая полезность, воспринимаемая простота использования и приписывание к использованию. Несмотря на то, что данная модель стала ведущей моделью для прогнозирования использования системы, она столкнулась с рядом критических замечаний - от слабой теоретической основы до простых детерминистских отношений. В нашей стране люди «третьего возраста» пользуются Интернетом значительно меньше, чем в западных странах. Количество людей «третьего возраста» как пользователей Интернета значительно меньше, чем у более молодого поколения пользователей. Выявлено, что компьютер и Интернет дают для пожилого человека новые возможности для его социализации в современное общество. Новые цифровые технологии служат средством для делового и личностного общения (коммуникации), позволяют разнообразить проведения досуга, поиска применения своих умений и знаний для работы, осуществления покупок услуг и товаров. В то же время, прослеживается и некоторый негативная сторона в связи с доступом к виртуальному пространству: повышается вероятность рисков, связанных с уязвимостью пользователей, которая может привести к нежелательным последствиям [4]. Проведенный анализ показал, что только 25\% респондентов дома имеют цифровую технику, это могут быть планшеты - 2,7\%, смартфона, коммуникатора, i-phone - 6,5\%, переносного компьютера (ноутбук, лэптоп, нетбук) - 10,3\%. А вот мобильные теле- фоны у 81,3\% [8]. За частую, пожилые люди, проживающие совместно с родственниками, пользуются их компьютерами и устройствами, но доля их мала всего 8,8\% общего числа опрошенных пожилых россиян. Так же пожилые люди используют интернет и подключение к нему в основном дома приблизительно 94,2\%, в других местах (7,0\%) и пользовались Интернетом в кафе с Wi-Fi - 2,2\%.

По данным Федеральной службы государственной статистики, «численность населения старше трудоспособного возраста, постоянно проживающего в России, по состоянию на 01.01.2016 составляла около 36 млн чел. Пожилые респонденты, которые используют виртуальное пространство (глобальная сеть), отвечали на вопрос об устройствах, которые они используют для выхода в Интернет: 58,3\% респондентов используют персональный компьютер, 49,7\%. для выхода в Интернет пользуются ноутбуком, лэптоп Мобильный Интернет, который подключен через телефон или смартфон используется 23,8\% пользователей сети» [5].

Возможности и угрозы при использовании цифровых технологий для людей «третьего возраста» (пожилых людей) требует пристального внимания и исследования положительного эффекта и рисков, которым они подвергаются при использовании данных технологий.

Выше проведенный анализ позволяет объединить поведенческие, функциональные и физические факторы с социально-демографическими показателями для оценки использования и неиспользования цифровых технологий пожилыми людьми. Проведенный анализ проблемы можно резюмировать тремя исследовательскими вопросами:

1. Какие факторы (установочные, функциональные и физические) связаны с использованием и неиспользованием цифровых технологий пожилыми людьми?

2. В чем различия между пожилыми пользователями цифровых технологий и не пользователями?

3. Какие социально-демографические показатели позволяют прогнозировать использование цифровых технологий пожилыми людьми?

Чтобы ответить на эти вопросы, следует решить следующие задачи: во-первых, проанализировать использование (и неиспользование) цифровых технологий, используя выборки людей старше 65 лет. Во-вторых, изучить причины, по которым пожилые люди используют и не используют цифровые технологии. В-третьих, разработать профиль для пользователей и непользователей, чтобы исследовать различия между ними; в-четвертых, проверить, какие социально-демографические показатели могут предсказывать использование цифровых технологий. 


\section{ЛИТЕРАТУРА}

1. Всемирный доклад о старении и здоровье // who URL: https://apps.who.int/iris/bitstream/handle/10665/186463/9789244565049_rus.pdf?sequence=10 (дата обращения: 10.03.2021).

2. Л.А. Даринская, Г.И. Молодцова, Н.Л. Москвичева Пожилой человек и цифровое пространство: точки соприкосновения? Человек и образование (3), 151-158. http://obrazovanie21.narod.ru/

3. Каждый пятый пенсионер НПФ «САФМАР» подает заявление на накопительную пенсию онлайн // САФМАР пенсионный фонд URL: https://www.npfsafmar. ru/press/news/21121 (дата обращения: 01.03.2021).

4. Российский мониторинг экономического положения и здоровья населения НИУ ВШЭ // RLMS HSE URL: http://www.cpc.unc.edu/projects/rlms (дата 06ращения: 01.03.2021).

5. Раздел «Демография». Численность и состав населения. Распределение населения по возрастным группам. // Официальный сайт Федеральной службы государственной статистики. URL: www.gks.ru/wps/wcm/connect/rosstat_main/rosstat/ru/statistics/population/demography/\# (дата обращения: 01.03.2021).

6. Тенденции развития интернета в России и зарубежных странах : аналитический доклад / Г.И. Абдрахманова, 0.Е Баскакова, К.0. Вишневский, Л.М. Гохберг и др.; Координационный центр национального домена сети Интернет, Нац. исслед. ун-т«Высшая школа экономики». - М.: НИУ ВШэ, 2020. 144 c. -300 экз.

7. Х Хорошо быть старым. 0 преимуществах пожилого возраста // BBC News, Русская служба URL: https://www.bbc.com/russian/society/2015/11/151127_vert_ fut_benefits_of_getting_older (дата обращения: 10.03.2021).

8. Корнилова Марина Владимировна Компьютерные и интернет-технологии в жизни пожилых людей: возможности и риски // Власть. 2018. №6.

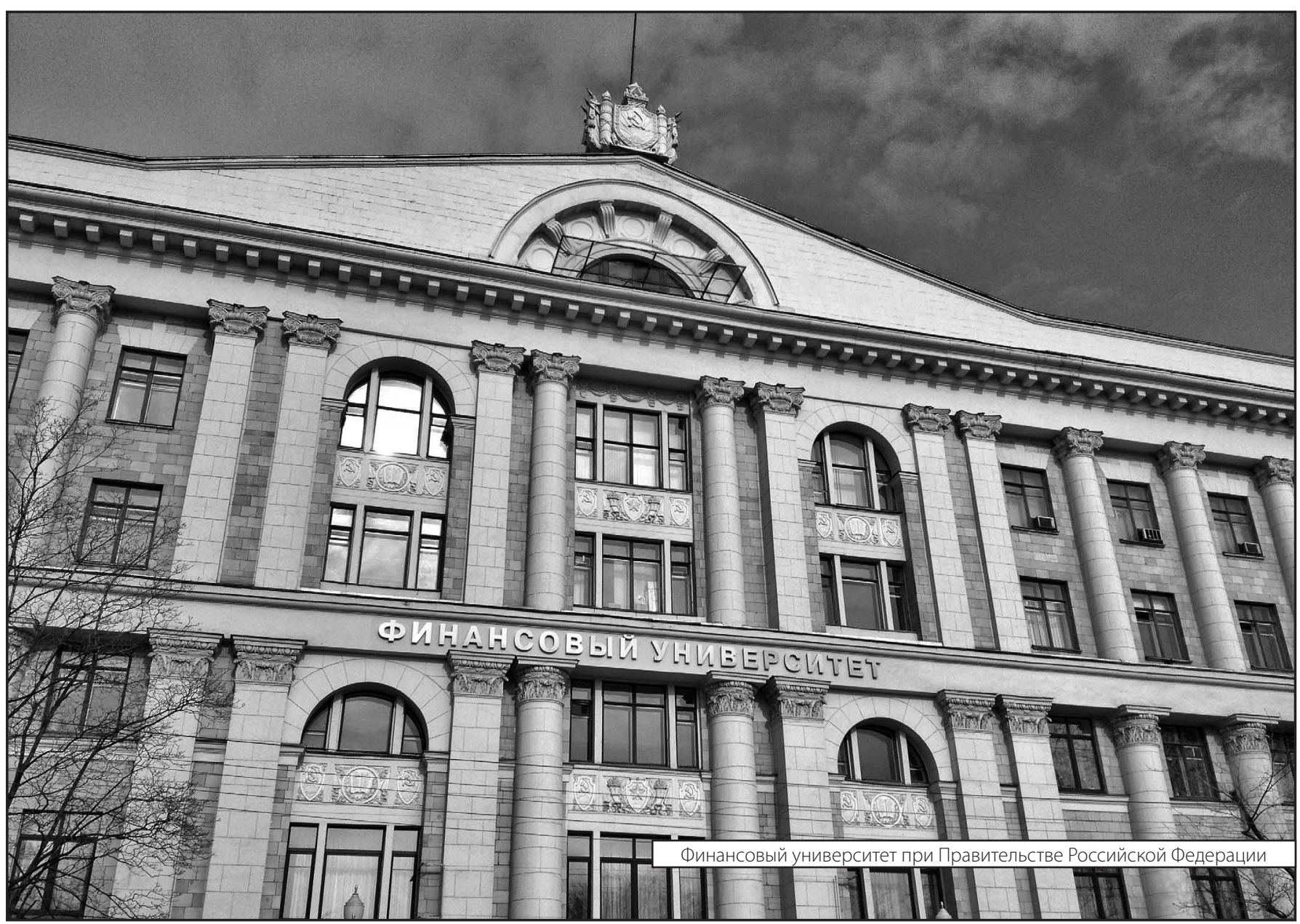

